\title{
Safety effects of low-cost engineering measures. An observational study in a Portuguese multilane road
}

\author{
Sandra Vieira Gomes*, João Lourenço Cardoso \\ Laboratório Nacional de Engenharia Civil, Department of Transportation, Av. Brasil, 101, 1700-066 Lisbon, Portugal
}

\section{A R T I C L E I N F O}

\section{Article history:}

Received 23 December 2009

Received in revised form 2 January 2012

Accepted 7 February 2012

\section{Keywords:}

Before-after study

Median

Low-cost engineering measures

Road safety

\begin{abstract}
A B S T R A C T
Single carriageway multilane roads are not, in general, a very safe type of road, mainly because of the high number of seriously injured victims in head-on collisions, when compared with dual carriageway multilane roads, with a median barrier.

In this paper the results of a study on the effect of the application of several low cost engineering measures, aimed at road infrastructure correction and road safety improvement on a multilane road (EN6), are presented. The study was developed by the National Laboratory of Civil Engineering (LNEC) for the Portuguese Road Administration and involved a comparison of selected aspects of motorized traffic behaviour (traffic volumes and speeds) measured in several sections of EN6, as well as monitoring of road safety developments in the same road. The applied low cost engineering measures allowed a reduction of $10 \%$ in the expected annual number of personal injury accidents and a $70 \%$ decrease in the expected annual number of head-on collisions; the expected annual frequency of accidents involving killed and seriously injured persons was reduced by $26 \%$.
\end{abstract}

(C) 2012 Elsevier Ltd. All rights reserved.

\section{Introduction}

The case study described in this paper refers to the analysis of the effect of several road safety measures undertaken on a Portuguese single carriageway multilane road (EN 6), following the construction of a new motorway (A5), parallel to the existing road, which links directly Lisboa to Cascais. Several low cost engineering measures were implemented thereafter, on a $3.7 \mathrm{~km}$ long stretch of EN6 (between $3.2 \mathrm{~km}$ and $6.9 \mathrm{~km}$ ) to improve its safety record.

The evaluation was carried through a "before-after" study with a control group. A stretch of another single carriageway multilane road (the EN125 in Algarve) was used as control group.

According to the Organization for Economic Co-operation and Development (OECD), integrated programmes on road safety aiming to reduce accident severity should focus on several traffic system elements, namely by adaptation of road environment characteristics to the intended road uses (OECD, 1984).

The application of road safety measures is based on general knowledge on the road safety phenomenon, sometimes complemented by results from the analysis of accident data in the area to be corrected.

\footnotetext{
* Corresponding author. Tel.: +35121 8443528; fax: +351218443029.

E-mail addresses: sandravieira@Inec.pt (S. Vieira Gomes), jpcardoso@lnec.pt (J.L. Cardoso).
}

Better results may be achieved with road safety interventions if procedures for their implementation include the following steps (Cardoso and Bairrão, 2001):

- Network safety diagnosis to identify locations with high influence of road characteristics on accident occurrence.

- Safety analysis on each selected location for potential interventions, to identify the main road characteristics leading to safety issues.

- Selection and application of appropriate safety measures.

- Safety monitoring of the corrected sites and evaluation of results.

The decision process for selecting corrective measures takes into account the available budget for the programme, the safety issues identified by the diagnosis and the anticipated benefits from the potential suitable measures. Monitoring safety developments following interventions and assessing the results obtained are very important steps for enhancing the efficiency of this type of process, since they allow the improvement of ex-ante benefit estimations, and consequently, better future investment decisions. This is especially relevant when the applied safety measures are transferred from other countries' traffic systems, due to the different response of drivers. This paper allows to increase the knowledge on the effects of safety interventions specifically applied in the Portuguese road environment, which can be different from other European countries due to particular driver behaviour. 